\title{
THE EXPERIENCE OF THE LEGISLATIVE REGULATION
} IN RUSSIA, KAZAKHSTAN AND CHINA ${ }^{1}$

\author{
Mikhail N. Kozyuk \\ Volgograd Institute of Management - Branch of the Russian Presidential Academy \\ of National Economy and Public Administration, Volgograd, Russian Federation
}

\begin{abstract}
Introduction: the problem of local self-government in Russia is the situation when there is no important link in the system of municipal relations - the local community. This leads to a lot of negative effects that are now increasingly referred to as the crisis of the local government. In particular, due to the increase in the conflict nature of the modern society, the social sciences face the practical problem of creating the effective technologies for its prevention and resolution at the lowest level of social organization. Goals and tasks: one of the promising technologies here is mediateness, or mediation in reconciliation. However, mediation has no prospects in the local community in the form it is introduced into the Russian society. Therefore, the author proposes to refer to the legislative experience of other countries in a similar situation: first of all, Kazakhstan and China, as these countries have their own laws on mediation. Methods: the comparative law analysis is used to study the experience of these countries. Conclusions: from the author's point of view, it is necessary to carefully study the Chinese experience as the most promising for Russia. In China, the function of organizing the removal of social conflict at the level of local communities is provided in the Constitution. Among the attractive points one can note the organizational clarity, certain flexibility of the organization and activity, as well as the logistical support for the activities of intermediaries, which are guaranteed by the state.
\end{abstract}

Key words: reconciliation, mediation, local community, mediators, people's mediators.

\section{ПРИМИРЕНИЕ В МЕСТНЫХ СООБЩЕСТВАХ: ОПЫТ ЗАКОНОДАТЕЛЬНОГО РЕГУЛИРОВАНИЯ РОССИИ, КАЗАХСТАНА И КИТАЯ ${ }^{1}$}

\author{
Михаил Николаевич Козюк \\ Волгоградский институт управления - филиал Российской академии народного хозяйства \\ и государственной службы при Президенте РФ, г. Волгоград, Российская Федерация
}

Введение: проблемой местного самоуправления России является ситуация, когда в системе муниципальных отношений отсутствует важное звено - местное сообщество. Это предопределяет множество негативных последствий, которые сейчас все чаще именуют кризисом местного самоуправления. В частности, в связи с повышением конфликтности современного общества перед социальными науками стоит практическая проблема создания эффективных технологий ее профилактики и разрешения на самом низовом уровне социальной организации. Цели и задачи: одной из перспективных здесь является технология медиации или посредничества в примирении. Однако в том виде, в котором медиация внедрена в российское общество, она не имеет никаких перспектив в местном сообществе. Поэтому автор статьи предлагает обратиться к законоخे дательному опыту других стран, находящихся в аналогичной ситуации: прежде всего Казахстана и Китая, ті поскольку эти страны имеют свои законы о медиации. Методы: для изучения опыта указанных стран применен сравнительно-правовой (компаративистский) анализ. Выводы: с точки зрения автора, необходимо тщательно изучить китайский опыт как наиболее перспективный для России. В Китае функция организации снятия социальной конфликтности на уровне местных сообществ определена в Конституции страны. Среди привлекательных моментов можно отметить организационную четкость, определенную гибкость организа- 
ции и деятельности, а также материально-техническую обеспеченность деятельности посредников, которую гарантирует государство.

Ключевые слова: примирение, посредничество, медиация, местное сообщество, медиаторы, народные посредники.

\section{Введение}

Местное сообщество (община), в объективном существовании которого усомниться трудно, тем не менее, практически не представлено в действующем отечественном законодательстве, несмотря на то что почти треть жителей страны - сельское население, живущее в условиях этой социальной общности. Вместе с тем одним из ярких признаков местного сообщества является то, что это форма солидарной жизни, которая не только объединяла людей для совместного существования и противостояния всяческим угрозам, но и создавала некое морально-этическое единство, снимая внутренние конфликтогенные факторы, способные разрушить данное единство. Различные способы, которыми это делалось, созданы в многовековой истории общины, и в типовом отношении очень похожи у всех народов. Медиация появилась на заре человеческой истории как потребность праобщины в сохранении социального мира в условиях кишащей смертельными угрозами окружающей действительности.

В России сейчас имеется специальное законодательство, целью которого является «гармонизация социальных отношений». Речь идет о федеральном законе «Об альтернативной процедуре урегулирования споров с участием посредника (процедуре медиации)» [5]. Однако данный закон, несмотря на его «широкоохватное» название, касается, по сути, только довольно узкой категории социальных конфликтов, прежде всего - предпринимательских. Создан он был, скорее всего, узкой группой юристов, специализирующихся на арбитражных спорах, и для своих профессиональных нужд. Породив поначалу некий энтузиазм, поскольку речь казалось бы шла о широком социальном движении в сторону миротворчества, примирения, толерантности и т. п., при своей реализации он показал, что посвящен довольно узкой специфической проблематике, и поэтому интерес к нему, в сущности, сходит на нет.

\section{Законодательство о примирении в сельских сообществах России, Казахстана и Китая}

Однако это не касается самого явления медиации или посредничества в примирении, которое затрагивает каждого человека, каждую семью, каждую социальную группу. И в этом отношении закон сделал некий «реверанс», определив, что наряду с профессиональными медиаторами могут существовать и непрофессиональные (ст. 15), к которым отнесены все дееспособные граждане, не имеющие судимости. Логику и смысл этого положения о непрофессиональном медиаторе уловить трудно, скорее всего, она была потеряна в процессе доработки и принятия закона. Однако примечательно, что его не исключили из закона совсем, как бы все-таки имея в виду, что в обществе возможна не только коммерческая медиация, но и социальная. При этом ч. 5 ст. 15 запретила государственным и муниципальным служащим заниматься медиацией, что сразу отсекло интерес к этой технологии у лиц, главная служебная обязанность которых в принципе - снятие социальной конфликтности. Поэтому в России и существует некая парадоксальная ситуация, когда и участковые уполномоченные полиции, и работники местной власти по мере сил и способностей стараются профилактировать не только межнациональные, но и иные социальные конфликты, а в случае необходимости выступать формально или неформально посредниками в разного рода конфликтных ситуациях, при этом, как правило, не догадываясь, что они занимаются запретной для них медиацией.

Вместе с тем Россия не является единственной страной с большим сегментом сельского населения с его традиционной общинной организацией. Среди наших ближайших соседей таковыми являются как минимум две огромные страны: Казахстан и Китай. Имея схожие проблемы, власти этих стран по-своему решают их с учетом в том числе и местных традиций. 


\section{ТЕОРИЯ И ПРАКТИКА ГОСУДАРСТВЕННО-ПРАВОВОГО РАЗВИТИЯ}

Закон Республики Казахстан «О медиации», как и российский, вступивший в силу в 2011 г. [3], в основном воспринял ту схему организации института медиации, которая реализована в России, правда, с несколько более подробным регулированием. Однако по интересующему нас вопросу есть разительные отличия. Так, ст. 15 называется «Проведение медиации членами местного сообщества». В п. 1 статьи говорится о том, что наряду с профессиональными медиаторами медиацию могут проводить избираемые собранием (сходом) местного сообщества для этих целей члены местного сообщества, имеющие большой жизненный опыт, авторитет и безупречную репутацию. Данные лица регистрируются уполномоченным органом, которым является аким (глава) района, поселка, села, сельского округа. Кроме них в этот реестр вносятся также иные лица, желающие заниматься медиативной деятельностью на непрофессиональной основе. Ст. 16 закона довольно подробно регулирует порядок ведения реестра непрофессиональных медиаторов. Необходимо отметить, что согласно закону о медиации она распространяется на гораздо больший перечень конфликтов, чем в России, включая сюда и уголовные преступления небольшой и средней тяжести, а также уголовные проступки. По сообщениям прессы, число непрофессиональных медиаторов в Казахстане превышает число профессиональных примерно в два раза. И поскольку наибольшее их количество зарегистрировано в преимущественно сельской местности, в отличие от городов, где их вообще не существует, то речь идет скорее всего о том, что селяне на своих сходах активно пользуются возможностью, предоставленной законом. Здесь также явно проявляется и элемент престижа, который играет большую роль в сельских сообществах. Ведь согласно закону, медиатор - человек имеющий «большой жизненный опыт, авторитет и безупречную репутацию». Вместе с тем кроме достаточно сложной системы попадания в реестр непрофессиональных медиаторов, все остальные вопросы их деятельности никак не регулируются, поэтому непрофессиональные медиаторы действуют вполне автономно. $\mathrm{C}$ точки зрения оплаты труда их отличие от профессиональных медиаторов, которым воз- мещаются все расходы и выплачивается вознаграждение, заключается в том, что непрофессиональному медиатору возмещаются только прямые расходы.

Таким образом, закон о медиации Республики Казахстан несколько продвинул идею социальной медиации, не забыв о специфике местных сообществ, однако начав регулирование института, законодатель, собственно, не довел его до логического конца. Также согласно закону, медиатором не может быть лицо «уполномоченное на выполнение государственных функций и приравненное к нему».

Однако особый интерес для анализа интересующей нас темы - урегулирования социальных конфликтов в сельском сообществе, вызывает законодательство Китайской Народной Республики. Здесь есть несколько аспектов. Во-первых, Китай - страна традиционно аграрная, и несмотря на рывок в индустриализацию нескольких последних десятилетий, тема организации и развития сельской жизни отнюдь не снята с повестки дня. Вовторых, законодательство Китая вполне самобытно и опирается скорее на традицию и здравый смысл, чем на модные зарубежные веяния [4]. Власти Китая четко разделяют, например, медиацию как процедуру для примирения в сфере предпринимательской деятельности высокого уровня и медиацию (примирение) для сельских сообществ. В-третьих, в законодательстве проявляется политический менталитет, очень знакомый россиянам по советским временам. Стилистика китайских законов напоминает советские акты 30-50-х гг. прошлого века, в которых упор делался не на формалистически организованный текст, а на сознательность, здравый смысл людей, которые будут исполнять законы. Причем в таком регулировании отнюдь нет утопических или идеалистических представлений о людях, которым, как известно «свойственно ошибаться». Скорее наоборот, акты предвидят, что ошибки неизбежны, однако последствия таких ошибок для лиц, их совершивших, отнюдь не роковые.

Первая поразительная особенность китайского законодательства состоит в том, что проблема преодоления социальной конфликтности в местном сообществе поднята на конституционный уровень регулирования. Так, 
ст. 111 Конституции КНР 1982 г. (с изм. 1988, 1993, 1999, 2004 гг.) говорит о том, что комитеты городского и сельского населения как низовые органы самоуправления образуют примирительные (конфликтные) комиссии, которые разрешают споры среди населения. На основании Конституции в 2010 г. был принят и вступил в силу, как и российский закон о медиации, с 1 января 2011 г. «Закон Китайской Народной Республики о посредничестве» [4]. Ст. 2 закона четко устанавливает, что «народное посредничество относится к процессу, при котором народные согласительные комиссии убеждают заинтересованные стороны в необходимости достижения примирительного соглашения на основе равных переговоров и доброй воли, что решит возникший между ними спор». Целью закона является сохранение социальной гармонии и стабильности. В этом смысле цели российского и китайского законов перекликаются. Согласно закону, в стране создается новый социальный институт «народные согласительные комиссии» - массовые организации, созданные на законной основе для урегулирования споров между людьми. По своему статусу народные согласительные комиссии (далее - НСК) являются государственно-общественными органами, создаваемыми населением и работающими под контролем отделов юстиции и народных судов низшего уровня.

В составе НСК могут работать от 3 до 9 членов, причем законом специально оговаривается, что в ней должны быть и женщины, и представители национальных меньшинств. Члены комиссии избираются на собраниях жителей или их представителей. Наряду с территориальными комиссиями могут создаваться примирительные комиссии в производственных коллективах. Срок работы членов комиссии -3 года с неограниченной возможностью переизбрания. Работа комиссии строится на принципах открытости для населения и подконтрольности ему, при этом комиссии не имею права взымать плату за урегулирование споров.

Народными посредниками выступают как члены комиссий, так и иные лица, нанятые комиссиями. При этом требования к посредникам достаточно обширны: совершеннолетие, беспристрастность, порядочность, преданность делу достижения согласия между людьми, определенный уровень образования, политическая грамотность и знание законов. Также посредники несут определенную законом ответственность за свои неправомерные действия, которые могут заключаться в следующем: фаворитизме к одной из сторон, оскорблении, взяточничестве, разглашении личной или коммерческой тайны. Причем в случае совершения таких проступков комиссия должна подвергнуть виновное лицо критике, «просветить и приказать ему исправиться». А если нарушение представляется серьезным, то организация, рекомендовавшая или назначившая лицо, должна освободить его от должности или занятия. Таким образом, на что мы обращали внимание выше, китайский закон говорит об ответственности и регулирует ее меры, чего нет, например, в российском законе.

Еще одно яркое отличие китайского закона от российского в том, что китайский регулирует не только условия, но и сам процесс медиации. Так, в нем устанавливается, что не только стороны могут обратиться к примирителю, но и сама комиссия, зная о конфликте, может добровольно предложить свои услуги. При этом стороны вправе отказаться. Кроме того, народные суд и полиция, рассматривая какое-либо дело и видя, что оно может быть разрешено посредниками, сами предлагают сторонам обратиться в НСК. В таких случаях НСК не только предоставляют свои услуги, но также могут быть организаторами примирения, привлекая к процедуре и других лиц. Ст. 22 закона в общем виде регламентирует действия посредников в процессе примирения: «Народные посредники могут предпринимать разные средства для урегулирования споров между людьми в свете реальных обстоятельств этих споров, заслушивать заявления заинтересованных сторон, разъяснять соответствующие законы, правила и государственную политику, терпеливо убеждать заинтересованные стороны, предлагать решения на основе равноправных переговоров и взаимопонимания между заинтересованными сторонами и помогать им в достижении примирительного соглашения по доброй воле сторон». При этом посредники фиксируют свои действия, ведя необходимое делопроизводство. 


\section{ТЕОРИЯ И ПРАКТИКА ГОСУДАРСТВЕННО-ПРАВОВОГО РАЗВИТИЯ}

Достигнутое соглашение о примирении оформляется устной договоренностью или письменно. Оно является обязательным для сторон и его выполнение контролируется НСК. В случае возникающих проблем в дело может вмешаться суд. Сами НСК никаких юрисдикционных прав не имеют.

Государственные отделы юстиции должны обеспечивать подготовку и повышение квалификации народных посредников, также они собирают статистические данные об их деятельности. Низовые народные суды привлекают посредников для участия в делах при судебном примирении, для присутствия в зале суда при рассмотрении таких дел, они совместно анализируют дела, обобщают практику, обмениваются опытом.

Посреднические традиции Китая имеют давние традиционные корни [1]. До принятия закона о посредничестве данную сферу регулировало несколько актов. Так, сами комитеты были учреждены «Положением о народных комитетах посредников», утвержденным в 1954 году. В 1989 г. было принято новое положение. До 1998 г. в Китае действовало 10 млн посредников. В 2000 г. ими было рассмотрено 5 млн гражданских споров, из них 94,8 \% были успешно завершены. Количество народных посредников в 2009 г. составило 4 млн 940 тыс. человек. В настоящее время в Китае действует около миллиона примирительных комиссий, которые разрешают около 90 \% всех конфликтных ситуаций между гражданами.

Следует отметить, что в традиционном обществе, каковым и является сельский Китай, способов снятия конфликтов довольно много. Как отмечает китайский ученый-юрист Чжан Цзюэ: «Кроме народного посредничества действуют: 1) примирение путем посредничества родственников, друзей, старшего поколения и высоконравственных и глубокоуважаемых людей; 2) примирение путем посредничества специалистов; 3 ) разрешение путем вмешательства органов власти; 4) другие способы, например, обращение за помощью к высшей власти» [6]. Вместе с тем происходящие социально-экономические процессы постоянно умножают как количество, так и сложность конфликтов, что ставит проблемы повышения эффективности системы примирения.

\section{Выводы}

Рассматривая перспективу развития медиативных технологий в России, есть опасение того, что процесс, начатый принятием федерального закона о медиации, постепенно будет свертываться. Вместе с тем необходимость подобной технологии, которую можно назвать социальной медиацией, широко востребована в конфликтном обществе. Однако эти процессы будут развиваться не на основе закона о медиации, а иными путями, благо, что и сам закон построен на диспозитивных нормах и, в общем-то, при аккуратном отношении к проблеме препятствий для широкого применения технологий посредничества в примирении не создает. Особо важным на наш взгляд было бы решение проблемы, описанной в статье - возрождение и укрепление традиций примирения в местных сообществах.

\section{ПРИМЕЧАНИЕ}

${ }^{1}$ Исследование проведено при финансовой поддержке РФФИ и Администрации Волгоградской области, проект «Медиативные технологии снижения социальной конфликтности в деятельности должностных лиц органов местного самоуправления Волгоградской области» № 16-13-34020.

\section{СПИСОК ЛИТЕРАТУРЫ}

1. Даньшин, А. В. Институт медиации в традиционном Китае (X-XIX вв.) / А. В. Даньшин // Исторические, философские, политические и юридические науки, культурология и искусствоведение. Вопросы теории и практики. - Тамбов : Грамота, 2014. - № 12-2 (50). - С. 42-46.

2. Закон КНР «О посредничестве». - Электрон. текстовые дан. - Режим доступа: http://asia-business.ru/ law/law3/agent/ (дата обращения: 01.09.2017). - Загл. с экрана.

3. Закон Республики Казахстан от 28 января 2011 года № 401-ІҮ «О медиации» : (с изм. и доп. по состоянию на 31.10.2015 г.). - Электрон. текстовые дан. - Режим доступа: http://online. zakon.kz/ Document/?doc_id=30927376 (дата обращения: 01.09.2017). - Загл. с экрана.

4. Трощинский, П. В. Современное законодательство КНР: проблемы и перспективы развития / П. В. Трощинский // Журнал зарубежного законодательства и сравнительного правоведения. 2016. -№ 3. - C. 24-31. 
5. Федеральный закон №193-Ф3 «Об альтернативной процедуре урегулирования споров с участием посредника (процедуре медиации)» от 27 июля 2010 г. // Собрание законодательства РФ. 2010. - № 31. - Ст. 4162 ; 2013. - № 27. - Ст. 3477 ; № 30. - Ст. 4066.

6. Чжан Цзюэ. Правовой и социологический механизм урегулирования конфликтов в китайском сельском сообществе / Чжан Цзюэ // Социологические исследования. 2014. - № 6. - С. 111-115.

\section{REFERENCES}

1. Danshin A.V. Institut mediatsii v traditsionnom Kitae (X-XIX vv.) [Mediation Institute in Traditional China $\left(10^{\text {th }}-19^{\text {th }}\right.$ Centuries $\left.)\right]$. Istoricheskie, filosofskie, politicheskie i yuridicheskie nauki, kulturologiya $i$ iskusstvovedenie. Voprosy teorii i praktiki [Journal of Historical, Philosophical, Political and Legal Sciences, Cultural Studies and Art History. Issues of Theory and Practice], 2014, no. 12 (50), part 2, pp. 42-46.

2. Zakon KNR «O posrednichestve» [The Law of the People's Republic of China "On Mediation"]. URL: http://asia-business.ru/law/law3/agent/ (accessed September 1, 2017).

3. Zakon Respubliki Kazahstan ot 28 yanvarya 2011 goda № 401-IY «O mediatsii»: (s izmeneniyami i dopolneniyami po sostoyaniyu na 31.10.2015 g.) [Law of the Republic of Kazakhstan of January 28, 2011 no. 401-IY “On Mediation” (with Amendments and Additions as of October 31, 2015)]. URL: http:// online.zakon.kz/Document/?doc_id=30927376 (accessed September 1, 2017).

4. Troshchinskiy P.V. Sovremennoe zakonodatelstvo KNR: problemy i perspektivy razvitiya [Modern Legislation of China: Challenges and Prospects for Development]. Zhurnal zarubezhnogo zakonodatelstva i sravnitelnogo pravovedeniya [Journal of Foreign Legislation and Comparative Jurisprudence], 2016, no. 3, pp. 24-31

5. Federalnyy zakon ot 27 iyulya 2010 g. №193-FZ «Ob alternativnoy protsedure uregulirovaniya sporov $\mathrm{s}$ uchastiem posrednika (protsedure mediatsii)» [Federal Law of July 27, 2010 no. 193-FL “On Alternative Dispute Settlement Procedure with the Involvement of a Mediator (Mediation Procedure)"]. Sobranie zakonodatelstva Rossiyskoy Federatsii [Collected Legislation of the Russian Federation], 2010, no. 31, art. 4162; 2013, no. 27 , art. 3477; no. 30, art. 4066.

6. Zhang Jue. Pravovoy i sotsiologicheskiy mekhanizm uregulirovaniya konfliktov v kitayskom selskom soobshchestve [Legal and Sociological Mechanism for Conflict Resolution in the Chinese Rural Community]. Sotsiologicheskie issledovaniya, 2014, no. 6, pp. 111-115.

\section{Information about the Author}

Mikhail N. Kozyuk, Candidate of Juridical Sciences, Associate Professor, Department of Theory and History of State and Law, Volgograd Institute of Management - Branch of the Russian Presidential Academy of National Economy and Public Administration, Gagarina St., 8, 400131 Volgograd, Russian Federation,mkozuk@yandex.ru.

\section{Информация об авторе}

Михаил Николаевич Козюк, кандидат юридических наук, доцент кафедры теории и истории права и государства, Волгоградский институт управления - филиал Российской академии народного хозяйства и государственной службы при Президенте РФ, ул. Гагарина, 8, 400131 г. Волгоград, Российская Федерация, mkozuk@yandex.ru. 